\title{
The Wealth-Health Nexus New Global Evidence
}

\section{Journal Article}

\section{Author(s):}

Jaunky, Vishal Chandr

Publication date:

2012-11

Permanent link:

https://doi.org/10.3929/ethz-b-000059046

\section{Rights / license:}

In Copyright - Non-Commercial Use Permitted

\section{Originally published in:}

Atlantic Economic Journal 41(2), https://doi.org/10.1007/s11293-012-9347-x 


\title{
The Wealth-Health Nexus: New Global Evidence
}

\author{
Vishal Chandr Jaunky
}

Published online: 14 November 2012

(C) International Atlantic Economic Society 2012

\begin{abstract}
Using a world sample of countries, this paper re-examines the U-shaped relationship between per capita GDP (wealth) and life expectancy at birth (health). Since cross-sectional dependence across countries is detected, second-generation panel unit root and cointegration tests are employed. All the variables are found to be integrated in one order as well as cointegrated. Various quadratic specifications are also employed and the hypothesis is confirmed.
\end{abstract}

Keywords Per capita GDP · Life expectancy · Cross-sectional dependence $\cdot$ Panel FMOLS

JEL $\mathrm{I} 15 \cdot \mathrm{C} 33 \cdot \mathrm{O} 11$

\section{Introduction}

Healthcare improvements constitute a major moral prerogative to any nation. Healthy citizens, whether unskilled or skilled, enhance an economy's productive capacity by being both physically and mentally apt. As such, the question of whether better health care can stimulate economic growth intrinsically arises. There is an on-going debate in literature on the impact of increased life expectancy on the wealth of nations and diverse results have been obtained.

Cervellati and Sunde (2011) theorized a non-monotonic connection between life expectancy and economic growth, "... in which the demographic transition represents an important turning point for population dynamics and hence plays a central

I would like to express my sincere thanks to Thomas F. Rutherford and Massimo Filippini, John Virgo and an anonymous referee for their comments on an earlier version of this paper. Errors, if any, are the author's own only.

V. C. Jaunky $(\triangle)$

Centre for Energy Policy and Economics, ETH Zurich, Zurichbergstrasse 18, 8032 Zurich, Switzerland

e-mail: vjaunky@ethz.ch 
role for the transition from stagnation to growth" (page 103). For instance, this concept is seen graphically illustrated in Fig. 1.

During infant stages of development, any improvements on the level of health lead to a fall in wealth because of the occurrence of the Malthusian population effect. The latter postulates an exponential expansion in population growth. Yet, this effect is only temporary as fertility is apt to drop. As further health improvements occur beyond the turning point $\alpha$, human capital accumulations and economic development are stimulated. This eventually causes population growth rate to fall (Hansen 2012).

Various studies have investigated the impact of life expectancy on economic growth. Acemoglu and Johnson (2007) find a negative but statistically insignificant impact whereas Zhang and Zhang (2005), Bloom et al. (2009), Turan (2009) and Aghion et al. (2010) uncover a significantly positive one. Hansen (2012) is among the first to provide evidence of a U-shaped relationship using a world panel of 119 countries throughout the period of 1940-1980. Yet, while the models used in literature rely heavily on cross-sectional studies which may not adequately capture the effects of health, some have employed panel data of little importance given to non-stationary series, which can lead to spurious inferences.

This paper revisits the implications of health on wealth by employing state-of-theart panel data techniques. Using the 2011 World Development Indicators data from The World Bank Group, 107 countries for the 1970-2009 period are selected. Table 1 shows the descriptive statistics for real gross domestic product (GDP) per capita (at constant 2000) and life expectancy at birth. Referring to Fig. 2, the scatter plot for the year 2009 does reflect a slight U-shaped relationship between the two variables.

\section{Results}

To investigate whether a U-shaped relationship exists, the following quadratic regression is run:

$$
L G D P_{i t}=\beta_{0}+\beta_{1} L E X_{i t}+\beta_{2} L E X_{i t}^{2}+\varepsilon_{i t},
$$

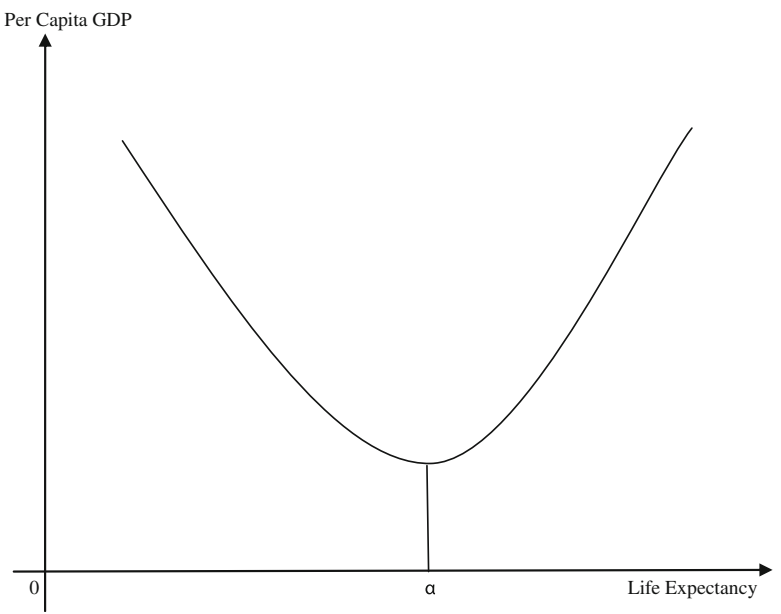

Fig. 1 The U-shaped hypothesis. Source: Computed 
Table 1 Descriptive statistics for the period 1970-2009

\begin{tabular}{lllll}
\hline Data & Mean & Standard deviation & Minimum & Maximum \\
\hline Real GDP per Capita (\$) & 6105.71 & 8738.81 & 57.78 & 56388.99 \\
Life Expectancy (years) & 63.68 & 11.46 & 26.82 & 82.93 \\
\hline
\end{tabular}

Computed

where $L G D P_{i t}$ denotes the natural logarithm of real GDP per capita for country $i$ and year $t$ and measures the level of wealth of in an economy. $L E X_{i t}$ denotes the natural logarithm of life expectancy at birth for country $i$ and year $t$. Also, it is used as a proxy for the general health conditions of a population (Acemoglu and Johnson 2007). $\beta_{1}$ and $\beta_{2}$ estimate the impacts of life expectancy on real GDP per capita. If a U-shaped relationship prevails between wealth and health levels, the expected outcomes will be $\beta_{1}<0$ and $\beta_{2}>0$. $\beta_{0}$ is the constant term while $\varepsilon_{i t}$ is the error term.

Prior to estimating the above equation, some preliminary tests are conducted. According to the Hausman's (1978) specification test, the null hypothesis $\left(\mathrm{H}_{0}\right)$ of no systematic difference in coefficients between the fixed-effects (FE) and randomeffects (RE) panel data models is rejected with the test statistics equal to $\chi^{2}(2)=$

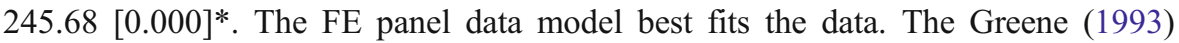
groupwise heteroskedasticity test statistics are $\chi^{2}(106)=15955.74[0.000]^{*}$ and $\chi^{2}(106)=15998.47[0.000]^{*}$ for the FE and RE panel data models respectively. Thus, the $\mathrm{H}_{0}$ of homoskedasticity is rejected. Next, the Wooldridge (2002) no firstorder autocorrelation $(\mathrm{AR}(1))$ test statistic is $\mathrm{F}(1,106)=289.25[0.000]^{*}$. The $\mathrm{H}_{0}$ is rejected. The Pesaran (2004) test of $\mathrm{H}_{0}$ no cross-sectional dependence (CSD) is equal to $38.02[0.000]^{*}$ for the FE panel data model. The p-value is in square brackets. The presence of CSD is found. In addition to the FE and RE panel data models, the Prais and Winsten (1954) heteroskedastic panel corrected standard error model which can control for AR(1) specific to each panel is applied (StataCorp 2007).

As exposed in Table 4, the U-shaped hypothesis is supported. Since $\beta_{1}$ and $\beta_{2}$ are statistically significant at the $1 \%$ level, a precise and meaningful value of $\alpha$ can

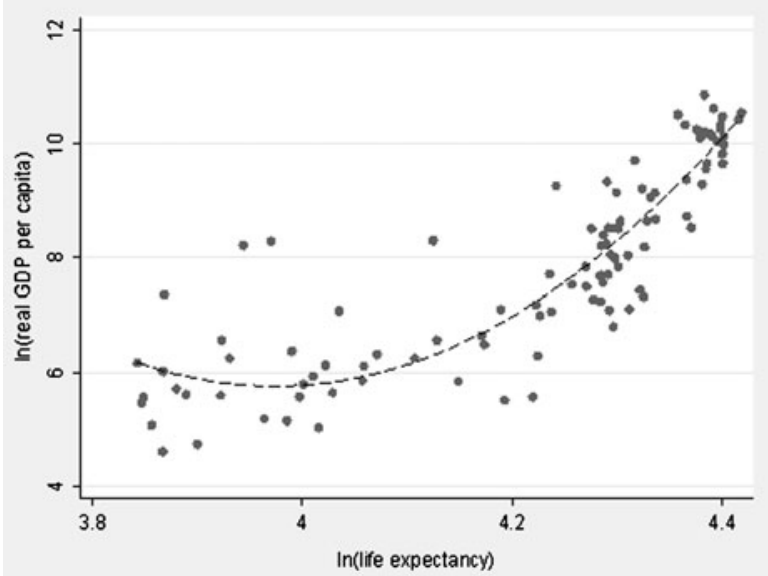

Fig. 2 Scatter diagram for the year 2009. Source: Computed 
be obtained from the models. For instance, a $99 \%$ confidence interval for $\alpha$ is reported for the FE, RE, and PW panel data models. All $\alpha$ 's are found to lie within this estimated interval. Their p-values are also computed to be 0.000 , implying they are statistically significant from zero. Nevertheless, these three models are based on the stationarity assumption and ignore any non-stationary process of the series which can result in spurious inferences. Efficient models such as the fully modified ordinary least squares (FMOLS) model need be considered. Preliminary tests such as panel unit root and cointegration tests are accordingly required. When performing panel unit root tests, two distinct specifications are utilized. One test includes a constant term only while the other contains both a constant term and a time trend. Macroeconomic data tends to display a trend over time. It is more fitting to consider a regression with a constant and a trend at level form. Since first-differencing tends to extract any deterministic trends, inferences will be carried out by considering a constant term only.

Pesaran (2007) recommends a test of the $\mathrm{H}_{0}$ of a unit root which allows for the presence of CSD patterns. To control for these patterns, the standard augmented Dickey-Fuller (ADF) regression models are augmented with the cross-sectional averages of the lagged levels and the first-differences of the individual series. The test is based on the cross-sectionally ADF (CADF) statistics. As revealed in Table 2 (a), the results from the Pesaran test corroborate with the earlier tests. All variables are once more found to follow an I(1) process. Kwiatkowski et al. (1992) recommend a test of the $\mathrm{H}_{0}$ of the stationarity hypothesis to complement the $\mathrm{H}_{0}$ of a unit root. Such joint testing is known as confirmatory analysis (Romero-Ávila 2008). The test of the $\mathrm{H}_{0}$ of stationarity as suggested by Hadri and Kurozumi (2012) is applied. This test allows the Lagrange multiplier (LM) test to control for CSD. Although it is similar to the KPSS test, the regression is augmented by the cross-sectional average of the observations à la Pesaran (2007). As illustrated in Table 2(b), both $Z A_{s p c}$ and $Z A_{l a}$ test statistics confirm an I(1) process for all three series.

Karlsson and Löthgren (2000) issue a caveat where the rejection of the panel unit root can be driven by a few stationary series and consequently the whole panel may erroneously be modelled as stationary. The Narayan and Popp (2010) time-series unit root tests ${ }^{1}$ of two breaks in the level and slope for $L G D P_{i t}, L E X_{i t}$ and $L E X_{i t}^{2}$ are performed where 12,17 , and 13 countries are found to be $\mathrm{I}(0)$ respectively. Per se, the Pesaran (2007) test is redone by excluding those countries and no major difference to the results is found. The Westerlund (2007) cointegration tests are next performed. $G a$ and $G t$ test statistics test the $\mathrm{H}_{0}$ of no co-integration for at least one of the crosssectional units. $P a$ and $P t$ test statistics use the pooled information over all of the cross-sectional units to test the $\mathrm{H}_{0}$ of no co-integration for the whole panel. To control for CSD, robust critical values are obtained through 5,000 bootstrap replications. As shown in Table $3, \mathrm{H}_{0}$ is rejected when referring to the $G t$ and $P t$ test statistics. These panel unit roots and cointegration tests form part of the second-generation tests as they can effectively control for CSD. The first-generation tests rely mainly on the assumption of cross-sectional independence.

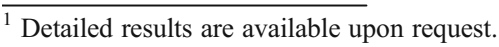


Table 2 (a): Pesaran panel unit root test statistics (b): Hadri and Kurozumi panel unit root test statistics

\begin{tabular}{llllll}
\hline Variables & Deterministics & Level form & \multicolumn{3}{c}{ First-difference } \\
& & $t$-bar & $Z$ & $t$-bar & $Z$ \\
$L G D P_{i t}$ & Constant & -1.399 & $4.192[1.000]$ & -2.161 & $-4.191[0.000]^{*}$ \\
& Constant + Trend & -2.001 & $3.987[1.000]$ & -2.487 & $-1.729[0.042]^{+}$ \\
$L E X_{i t}$ & Constant & -1.779 & $0.011[0.504]$ & -2.346 & $-6.233[0.000]^{*}$ \\
& Constant + Trend & -2.317 & $0.271[0.607]$ & -2.462 & $-1.432[0.076]^{*}$ \\
$L E X_{i t}^{2}$ & Constant & -1.798 & $-0.198[0.422]$ & -2.342 & $-6.186[0.000]^{*}$ \\
& Constant + Trend & -2.308 & $0.372[0.645]$ & -2.468 & $-1.507[0.066]^{*}$ \\
Variables & Deterministics & Level form & & First-difference \\
& & $Z A_{s p c}$ & $Z A_{l a}$ & $Z A_{s p c}$ & $Z A_{l a}$ \\
$L G D P_{i t}$ & Constant & -0.098 & -0.063 & 0.092 & 0.208 \\
& Constant + Trend & $3.935^{*}$ & $3.730^{*}$ & $1.820^{+}$ & $2.144^{*}$ \\
$L E X_{i t}$ & Constant & -1.995 & -1.982 & -1.119 & -1.212 \\
& Constant + Trend & $4.264^{*}$ & $4.334^{*}$ & $3.906^{*}$ & $3.772^{*}$ \\
$L E X_{i t}^{2}$ & Constant & -1.980 & -1.969 & -1.120 & -1.197 \\
& Constant + Trend & $4.585^{*}$ & $4.644^{*}$ & $4.159^{*}$ & $4.066^{*}$ \\
\hline
\end{tabular}

Computed. Note: The Bartlett kernel which is equal to $4(T / 100)^{2 / 9} \approx 4$ is used for the lag order. Critical values for the $t$-bar statistics without and with trend at $1 \%, 5 \%$ and $10 \%$ significance levels are -2.140 , -2.060 and -2.010 ; and $-2.620,-2.540$ and -2.500 respectively. The normalized $Z$ test statistic is compared to the $1 \%, 5 \%$ and $10 \%$ significance levels with the one-sided critical values of -2.326 , -1.645 and -1.282 correspondingly. ${ }^{*},{ }^{+}$and ${ }^{*}$ denotes $1 \%, 5 \%$ and $10 \%$ significance level correspondingly. P-value is given in square brackets. The $\mathrm{H}_{0}$ of stationarity is tested. The $Z A_{s p c}$ and $Z A_{l a}$ test statistics are compared to the $1 \%, 5 \%$ and $10 \%$ significance levels with the one-sided critical values of $2.326,1.645$ and 1.282 respectively. Following Kwiatkowski et al. (1992), the number of lags is set on the order of $T^{1 / 2} \approx 7$

The panel FMOLS estimates are presented in Table 4. The latter can effectively deal with both serial correlation and heteroskedasticity of residuals while controlling for any potential endogeneity of regressors. For instance, while health improvements can be positively related to income, the reverse is also true. Higher incomes make healthy goods and services such as good nutritious diet, proper sanitation, high-tech

Table 3 Westerlund panel cointegration test statistics

\begin{tabular}{|c|c|c|c|c|c|c|c|c|}
\hline \multirow[t]{2}{*}{ Statistics } & \multicolumn{4}{|c|}{ Without trend } & \multicolumn{4}{|c|}{ With trend } \\
\hline & Value & $Z$ & P-value & Robust P-value & Value & $Z$ & P-value & Robust P-value \\
\hline$G t$ & -2.737 & -13.378 & $0.000 *$ & $0.000 *$ & -3.729 & -14.769 & $0.000 *$ & $0.000 *$ \\
\hline$G a$ & -4.076 & 3.306 & 1.000 & $0.037^{+}$ & -4.489 & 12.901 & 1.000 & 1.000 \\
\hline$P t$ & -16.084 & -4.810 & $0.000 *$ & $0.000 *$ & -25.647 & -2.199 & $0.014^{+}$ & $0.027^{+}$ \\
\hline $\mathrm{Pa}$ & -2.988 & -1.033 & 0.151 & $0.001 *$ & -5.428 & 7.743 & 1.000 & 0.970 \\
\hline
\end{tabular}

Computed. Note: All these statistics are distributed standard normally. Critical values of one-sided tests for $1 \%, 5 \%$ and $10 \%$ significance levels are $-2.326,-1.645$ and -1.282 respectively. The lag and lead lengths are set to one 


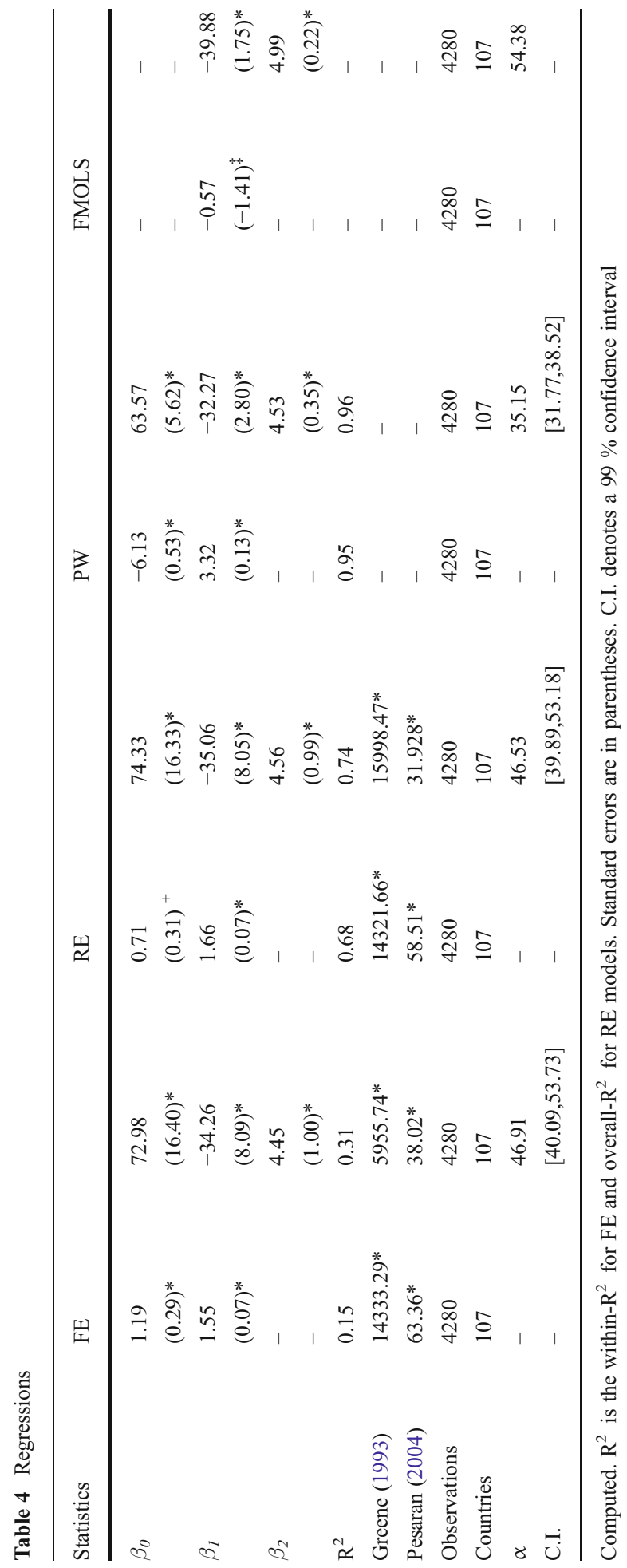


medical care, etc., more accessible and generate greater longevity. Healthcare may potentially be considered as endogenous and this may produce biased estimates. Moreover, to control for CSD, common time dummies are included (Pedroni 2001). A negative impact of health on wealth is first encountered. On the other hand, when considering the possibility of a non-linear relationship, wealth is found to be on a Ushaped path in the country level of health. Additionally, the panel FMOLS model reveals a turning point at around 54 years of life expectancy as compared to only 35 or 47 years as per the conventional models.

\section{Conclusions}

The paper investigates the relationship between wealth and health status using a world panel data for the period 1970-2009. A U-shaped relationship is uncovered. However, conventional estimators reveal a turning point of about 35 and 47 years, while a much greater value of 54 years is obtained when applying an efficient estimator such as the panel FMOLS. In sum, health effects on wealth are inclined to vary over different stages of economic development. Policymakers should therefore take for this non-monotonic relationship into account when designing healthcare schemes.

\section{Appendix}

List of countries: Algeria, Argentina, Australia, Austria, Bahamas, Bangladesh, Barbados, Belgium, Belize, Benin, Bolivia, Botswana, Brazil, Burkina Faso, Burundi, Cameroon, Canada, Central African Republic, Chad, Chile, China, Colombia, Congo DR., Congo Rep., Costa Rica, Cote d'Ivoire, Denmark, Dominican Rep., Ecuador, Egypt, Arab Rep., El Salvador, Fiji, Finland, France, Gabon, Gambia, Georgia, Germany, Ghana, Greece, Guatemala, Guinea-Bissau, Guyana, Honduras, Hong Kong, China, Hungary, Iceland, India, Indonesia, Iran Islamic Rep., Ireland, Israel, Italy, Jamaica, Japan, Kenya, Korea Rep., Latvia, Lesotho, Liberia, Luxembourg, Madagascar, Malawi, Malaysia, Mali, Malta, Mauritania, Mexico, Morocco, Nepal, Netherlands, Nicaragua, Niger, Nigeria, Norway, Oman, Pakistan, Panama, Papua New Guinea, Paraguay, Peru, Philippines, Portugal, Rwanda, Saudi Arabia, Senegal, Sierra Leone, Singapore, South Africa, Spain, Sri Lanka, St. Vincent and the Grenadines, Sudan, Swaziland, Sweden, Syrian Arab Rep., Thailand, Togo, Trinidad and Tobago, Tunisia, Turkey, United Kingdom, United States, Uruguay, Venezuela, Zambia, Zimbabwe.

\section{References}

Acemoglu, D., \& Johnson, S. (2007). Disease and development: the effect of life expectancy on economic growth. Journal of Political Economy, 115(6), 925-985.

Aghion, P., Howitt, P. \& Murtin, F. (2010). "The relationship between health and growth: When Lucas meets Nelson-Phelps," NBER Working Paper 1581. Online at: http://www.ofce.sciences-po.fr/pdf/ dtravail/WP2009-28.pdf.

Bloom, D.E., Canning, D. \& Fink G. (2009). "Disease and development revisited," NBER Working Paper No. 15137. Online at: http://www.nber.org/papers/w15137.pdf. 
Cervellati, M., \& Sunde, U. (2011). Life expectancy and economic growth: the role of the demographic transition. Journal of Economic Growth, 16(2), 99-133.

Greene, W. H. (1993). Econometric analysis (2nd ed.). New York: Macmillan Publishing Company.

Hadri, K., \& Kurozumi, E. (2012). A simple panel stationarity tests in the presence of cross-sectional dependence. Economics Letters, 115(1), 31-34.

Hansen, C. W. (2012). The relation between wealth and health: evidence from a world panel of countries. Economics Letters, 115(2), 175-176.

Hausman, J. A. (1978). Specification tests in econometrics. Econometrica, 46(6), 1251-1272.

Karlsson, S., \& Löthgren, M. (2000). On the power and interpretation of panel unit root tests. Economics Letters, 66(3), 249-255.

Kwiatkowski, D., Phillips, P., Schmidt, P., \& Shin, Y. (1992). Testing the null hypothesis of stationarity against the alternative of unit root. Journal of Econometrics, 54(1-3), 159-178.

Narayan, P. K., \& Popp, S. (2010). A new unit root test with two structural breaks in level and slope at unknown time. Journal of Applied Statistics, 37(9), 1425-1438.

Pedroni, P. (2001). Purchasing power parity tests in cointegrated panels. The Review of Economics and Statistics, 83(4), 727-731.

Pesaran, M.H. (2004). "General diagnostic tests for cross section dependence in panels." Cambridge Working Papers in Economics, 0435, Online at: http:/www.econ.cam.ac.uk/faculty/pesaran/ CDtestPesaranJune04.pdf.

Pesaran, M. H. (2007). A simple panel unit root test in the presence of cross-section dependence. Journal of Applied Econometrics, 22(2), 265-312.

Prais, S.J. \& Winsten C.B. (1954). "Trend Estimation and Serial Correlation." Cowles Commission Discussion Paper No. 383, Chicago.

Romero-Ávila, D. (2008). A confirmatory analysis of the unit root hypothesis for OECD consumption income ratios. Applied Economics, 40(17), 2271-2278.

StataCorp. (2007). Stata Statistical Software: Release 10. College Station: StataCorp LP.

Turan, B. (2009). "Life Expectancy and economic development: Evidence from micro data." Working Paper. Online at: http://www.uh.edu/ bkturan/lifeexpec.pdf.

Westerlund, J. (2007). Testing for error correction in panel data. Oxford Bulletin of Economics and Statistics, 69(6), 709-748.

Wooldridge, J. M. (2002). Econometric analysis of cross section and panel data. Cambridge: MIT Press.

Zhang, J., \& Zhang, J. (2005). The effect of life expectancy on fertility, saving, schooling and economic growth: theory and evidence. Scandinavian Journal of Economics, 107(1), 45-66. 